According to my experience, the easiest way of procuring an artificial digestive solution is to simply dry the stomach of an animal, and make an infusion of it whenever required, treating it with the requisite amount of acid. Where the stomach is thin, it may be cleansed with water and taken entire; but where, as in the case of the pig, the stomach is exceedingly thick, I strip away the mucous membrane from the muscular layer, and, spreading it out, allow it to dry spontaneously, or at a suitable distance from a fire. Cut into shreds, it may be preserved in a convenient form for use. Upon one occasion I experimented with different quantities of the dried mucous membrane thus obtained from the stomach of a pig. Twenty, ten, and five grains were taken, and treated respectively with one ounce of water and twenty minims of hydrochloric acid. Frogs' legs being introduced, they were all exposed together to a temperature of $11.0^{\circ}$. At the end of an hour and three-quarters, the twenty-and ten-grain specimens had produced strong marks of action upon the skin. In three hours, all three specimens bad led to the muscles being dissected out and the bones exposert. In eight hours all the legs were amputated at the surface of the liquid, and, with the exception of a few small fragments, had entirely disappeared. The quantity of pure pepsine, then, required for digestion is very minute.

Before I finish with the stomach as connected with primary assimilation, there is one other point I cannot refrain from touching upon-the immunity from digestion which the organ itself enjoys during life: a subject, I believe, that could not elicit from us a more profound consideration than it really de. serves. The position is this:- The stomach receives in its cavity materials constituted like its own parietes. The materials are dissolved or liquefied, whilst the stomach itself remains intact. What, it may be asked, is the explanation of such an elective result? A vessel is used holding a material identical with itself whilst a process of solution is being accomplished : the one is dissolved, and the other is not. For instance, say a vase of marble has fragments of marble placed in it to be dissolveu by an acid, and the fragments disappear, whilst the vessel remains intact. What can be brought forward satisfactorily to account for the immunity which, under such circumstances, the stomach enjoys? It was our countryman, John Hunter, who first directed attention to this point. In his communication published in the "Philosophical Transactions" for 1772, entilled "On the Digestion of the Stomach after Death," he remarks that in occasional instances, especially in persons who have died of sudden and violent deaths, on making an inspection of the body, the great extremity of the stomach is found so dissolved as to have allowed of the escape of i.s contents into the abdominal cavity. He also notices that, although a perforation of the stomach may not be observed, yet there are very few dead bodies in which the stomach is not at its greater end in some degree digested; this partial digestion being indicated by a thinness and transparency of the membranes, and by the blood which the vessels contain passing out at their digested ends when pressure is made from the larger towards the smaller branches, and appearing like drops on the inner surface.

The greatest extent of solution being observed in cases where the individual had been in the enjoyment of perfect health up to the moment of death, Hunter inferred that the phenomenon could not be the result of disease during life, but must be owing to an action exerted by the digestive fluid after the occurrence of death. If, then, the stomach were thus susceptible of being digested by its own secretion after death, the question imme. diately arose-What afforded it immunity from undergoing the same process of digestion during life? To Hunter it was the "living principle" that formed the required source of protection. To use his words, "The stomach, which at one instant -that is, while possessed of the living principle-was capable of resisting the digestive powers which it contained, the next moment--namely, when deprived of the living principle-is itself capable of being digested, either by the digestive powers of other stomachs, or by the remains of that power which it had of digesting other things." In illustration he says, "If it were possible for a man's hand to be introduced into the stomach of a living animal and kept there for some considerable time, it would be found that the dissolvent powers of the stomach could have no effect upon it; but if the same hand were separated from the body and introduced into the same stomach, we should then find that the stomach would immediately act upon it."

I have before me preparations of human stomachs belonging to the museum of Guy's Hospital, where considerable-sized deficiencies exist, the result of gastric solution. The same cun- dition is easily produced artificially wi h the lower animals. Under ordinary circumstances, although it is common to find the inner surface at the cardiac extremity bearing more or less evidence of attack by digestion, yet I think I have never witnessed that an actual perforation has taken place. If, however, when an animal has been killed during digestion, the temperature be afterwards maintained artificially, the result is far otherwise With this stomach, which bas been derived from the pig, the animal was killed whilst the organ was full, food having been purposely administered a few hours previous to death. The stomach, being simply removed with its contents, was suspended, by means of a string tied around its cesophageal and pyloric openings, in a large preparation glass, and exposed to a temperature of about $100^{\circ}$. Its contents were found some hours afterwards at the bottom of the glass, and upon looking at the organ itself there is an enormous rent which was produced by gastric solution.

I have here also a rabbit, in which the most extensive ravages have been produced by the digestive action of the gastric juice. The animal was killed about four hours after the ingestion of food. Its body was then placed in a warm situation, so that its temperature was maintained for several hours (about ten or twelve) quite equal to, or beyond that belonging to life. On opening the animal, the view displayed was truly remarkable. The stomach had completely disappeared, and its contents were dispersed over the peritoneal cavity; a portion of the liver was attacked and dissolved away; the greater part of the diaphragm was gone, and the ribs on the left side (the animal had been laid on this side) bared or completely dissected out; tho gastric juice escaping from the chest, the flesh about the neck and upper extremity on the left side had been acted upon, and was in a state of disintegration, so that the slightest force was sufficient to pull the parts asunder. It is truly astonishing the effect produced under these circumstances by the solvent influence of the gastric juice.

ON THE

\section{ACTION OF THE HYPOPHOSPHITES OF SODA AND LIME,}

THE SO-CALLED "SPECIFIC" FOR TUBERCULAR DISEASES.

By RICHARD PAYNE COTTON, M.D., F.R.C.P., PHYSICTAN TO THE HOSPITAL FOR CONSUMPTION, BROMPTON.

IN a paper read by Dr. Churchill before the Académie Impériale de Médecine in the year 1857, it is confidently stated that " the immediate cause, or at least an essential condition, of the tubercular diathesis consists in the diminution in the system of phosphorus in an oxydizable state," and that "the specific remedy for this disease is a preparation of phosphorus at the lowest possible degree of oxydation." Now, although such a statement was not based upon either chemical, physiological, or pathological investigation, but was purely hypothetical, yet I thought it might be desirable to test the efficacy of Dr. Churchill's treatment, and to publish the results, which, alas! were very uncomplimentary to the new "specific."* Dr. Charchill, however, having complained that this trial of him new remedy was of insufficient duration, I have thought it but fair to repeat the experiments, and at the same time to explain that the sole cause of the brevity on the former occasion was due to Dr. Churchill's own statements. We were informed in his paper that "even from the first day of taking the hypophosphites they produce a manifest increase of nervous power, together with an unusual feeling of comfort and strength : the appetite increases, the perspirations cease, sleep becomes calm and profound," \&c. Now, as I failed to observe any such consequences in any one of my patients within two, or at most three, weeks of their taking the hypophosphites, I considered that it would be unjustitiably trifling with the disease to give a longer trial to the treatment.

Shortly after this, my colleagne, Dr. Quain, published in Trre LANC $T$ the results of a far more elaborate series of experiments with the hypophosphites, $f$ and came to the conclusion that * Medical Times, Feb. $13 \mathrm{~h}, 1858$.
+ Tez Lancet, Mlarch $17 \mathrm{th}, 1860$. 
they were " comparatively, if not absolutely, useless ;" adding that he had known "much time thrown away by substituting the use of these salts for remedies of undoubted efficacy in controlling the progress of phthisis."

Dr. J. Risdon Bennett has also tried the hypophosphites in some carefully made experiments, and came to the conclusion that they had "no specific nor anti-tubercular action, no special influence being exerted by them on any one function of the body."

My recent experiments with the hypophosphites were made upon twelve of my own in-patients of the Consumption Hospital. These were selected, as will be seen, on account of their presenting nearly every possible conditinn both of the disease and of the circumstances of treatment. Two were unpromising cases, but most of them were promising; some had already improved under treatment; whilst in others no previous remedies seemed to have had much effect. In fine, I sought, in as complete a manner as possible, to ascertain whether the much-vaunted hypophosplites deserved what had been claimed for them, the title of "specific."

In order to aroid any pussible donbt as to the purity of the hypophosphites with which I experimented, I applied to Mr. Swann, of the Rue Castiglione, $P$ ris, the acknowledged maker of Dr. Churchill's phosphatic salts, who most obligingly and gratuitously forwarded a large case of them for trial at the Consumption Hospital.

In accordance with Dr. Churchill's directions, a tablespoonful of the syrup of the hypophosphite either of soda or lime was administered twice and sumetimes thrice a day. Notes of the cases were regularly taken by Dr. Rutter, resident clinical assistant at the hospital.

Before making any general comment upon the treatment, I shall give, as briefly as possible, a sketch of the twelve cases.

Case 1.-Phthisis, third stage; disease advancing under general tonics; hypophosphites three wetks; no change in symptoms. - R. B-_, aged twenty-one, gardener, admitted sept. 15th, 1862. Has been in ill health two years; cough severe; hæmoptysis twelve months ago; much emacialed; pulse 100 ; digestive organs healthy.

The physical signs denoted the first stage of tubercle on the right, and the third stage on the left side; the percussion under the right clavicle being dull and the respiration harsh, whilst nnder the left clavicle there was gurgling rhonchus with cavernous breathing.

Treatment. - For two months after admission, steel, quinine, and other tonics, with cod-liver oil, were successively tried, but with no good effect, the patient gradually losing both in health and weight. Half an ounce of the syrup of hypophos. phite of soda was then given twice a day for ten days, when diarrhoea came on, and the medicine was temporarily discontinued. It was afterwards tried for another ten days without any good result. No change occurred in any of the symptoms under the use of the hypophosphite; there was no improvement either in the appetite or strength, and the patient left the hospital with the disease advancing.

CASE 2.-Phthisis, first stage; disease advancing under the use of mineral acids, tonics, and cod liver oil; hypophosphites four weeks; no improvement.-R. R-, aged thirty-two, coachman, admitted Sept. 15th, 1862 . Has been gettiug thinner for several months; severe congh with frequent hæmoptysis-"spat up one pint three months ago ;" great expectoration; no night perspirations; bowels natural; pulse 96.

The physical signs were, barsh respiration with creaking under the right clavicle ; and weak respiration, with prolonged expiration, under the other clavicle.

Treatment. - During nine weeks the mineral acids and gentian, quinine, and cod-liver oil had been given unsuccessfully, the patient only becoming worse. Half an ounce of syrup of hypophosphite of soda was then given twice and sub. sequently three times a day, and continued for four weeks, without any sensible change in any of the symptoms; the patient, on leaving the bospital, expressing himself as unrelieved, "the cough as bad as at first, and the breath shorter than ever."

CASE 3.-Phthisis, first stage; hypophosphite of lime four weeks, followed by steel for six weeks; hypophosphites again for three weeks; considerable improvement both in local and genercal symptoms. - T. M - , aged thirty-six, labourer, admitted Nov. 1st, 1862. Has been out of bealth and getting thinner nine months; cough frequent and severe; breathing short hæmoptysis seven months ago; appetite bad; pains at epi gastrium and between shoulders; digestive organs feeble pulse 96. Father died of phthisis. Has lived very poorly, sel lom tasting meat.

Physical signs. - Respiration harsh and expiration prolonged, with much sub crepitant rhonchus under the right clavicle.

Treatment. - Half an ounce of the syrup of hypophospbite of soda was given, at first twice, and shortly afterwards thrice, a day for four weeks, together with full diet and porter. At the end of this time the patient felt much stronger and better, and had gained seven pounds in weight, although be still coughed and suffered from dyspncea. Fifteen drops of the tincture of sesquichloride of iron in water were then given twice a day for six weeks, during which time he continued to improve and gained two pounds more in weight. The hypophosphite was then resumed for three weeks, with continued in provement, but no further increase of weight. The patient was now greatly relieved; his health and strength fairly restored; his cough bad disappeared, together with all secretionsound in the right lung. On being questioned as to which mericine had done him most service, he said he had "felt as well under one as the other." It appeared to us all, indeed, that the change from farm-work and scanty diet to the rest and good living at the hospital was the main cause of this poor man's improvement.

CASE 4.-Plthisis, first stage; hypophosphite of lime three week:s-no improvement; steel for th'ee weeks-slight improvement; hypophosphite again for three weeks-no improvement. T. ' $1-$, carpenter, aged twenty-tbree, admitted Oct. 9th, 182 . Severe congh for twelve months; emaciation; hæmoptysis some weeks back; nausea and loss of appetite ; dyspnœa night perspirations; pulse 104. Brother died of phthisis.

Physical signs. - Harsh respiration, with sub-crepitans rhonchus under right clavicle; blowing and harsh respiration under left clavicle.

Treatment.-Half an ounce of syrup of hypophosphite of soda twice and afterwards thrice a day; and, for the cough, a small dose of syrup of morphia occasionally. This was continued for three weeks without alteration in any of the symptoms, and it was evident, both from general and physical signs, that the disease was steadily advancing. Ten minims of the tincture of sesquichloride of iron, with some cod-liver oil, were then given three times a day for three successive weeks, at the end of which time the patient expressed himself as being "better altogether since taking the new medicine." As, however, no very marked improvement seemed to exhibit itself, the hypophosphite was resumed for three weeks, when, the patient feeling that he was gaining but little by residence in the hospital, wished to be discharged. Upon being asked which medicine suited him best, he unhesitatingly said, "the steel."

CASE 5.-Phthisis, third stage; hypophosphite of soda five weeks-grcat improvement; hypophosphite exchanged for a mixture of carbonate of soda with syrup for four weeks-continued improvement. - E. C-, servant girl, aged seventeen, admitted Nov. 3rd, 1862. Ill ten months with cough; dyspnoea on exertion; occasional hrmoptysis ; appetite bad; is very low and feeble; pulse 100. Sister died of consumption.

The physical signs denoted a considerable cavity at the apex of the right lung, with tuberculosis in its first stage at the apex of the other lung.

Treatment.- Half an ounce of syrup of hypophosphite of lime twice a day, to which was added, on account of the severity of the cough, a sedative mixture composed of chloric ether and morphia. After taking this for five weeks, there was a manifest improvement; the congh had diminished, the health was better, and the patient had gained over two ponnde in weight. The hypophosphite was then changed for a mixture composed of two scruples of carbonate of soda, three ounces of syrup, and five ounces of water, which was continued for a month, when the patient was discharged, greatly improved in all respects, and having gained altogether five pounds in weight. No falling off was observed when the hypophosphite was dis. continued, the general improvemen ${ }^{2}$ persistmg, and the patient failing to discover the change. In this case, rest, hygiene, and gool diet probably deserve the chief credit; but it is very likely that the simple alkali, whether combined with the hypophosphorous or carbonic acid, was not an unimportant auxiliary by producing some salutary effect upon the organs of digestion.

CASE 6.-Phthisis, first stage; hypophosphite of lime seven weeks-improvement; steel, two weeks-falling off ; a mixture composed of syrup and carbonate of soda for four weeks-renewed improvement. - L. C- - , servant, aged thirty-one, ad. mitted Oct. 3rd, 1862 . Out of health twenty months; congh; no hæmoptysis; loss of weight; dyspncea on exertion; digestion 
good; catamenia absent seven months; pules 80 ; no hereditary predisposition.

Physical signs. - Respiratiun weak, with abundant sub-crepitant rhonchus at apex of right lung; respiration blowing, with sub crepitant rhonchus at apex of left lung.

Treatment. - Half an ounce of syrup of hypophosphite of soda was given twice, and subsequently three times a day, with codliver oil twice a day, as she had taken this before admission, and was unwilling to discontinue it. Full diet and ale. All this was continued for seven weeks, during which time the patient steadily improved, losing the cough, and gaining four pounds in weight. Ten minims of the sesquichloride of iron was then taken for a fortnight, but it appeared to disagree and occasion headache. A mixture, cornposed of carbonate of soda, syrup, and water, undistinguishable from the syrup of the hypophosphite of soda, was then taken for a month, during which time the patient improved greatly, both in her general and pulmonary symptoms, and believed she was taking the medicine as first prescriber. She then left the hospital, calling herself "quite well," and having gained six pounds in weight. The repose, comfort, and good living of the hospital unquestionably effected much in this patient. She would not bear steel, and evidently required a more simple treatment; but not the slightest difference was observable, whether she was taking the hypophosphite or the carbonate of soda.

CaSE 7.-Phthiiis, first stage; hypophosphite of soda six weels - no improvement; steel six weeks-slight improvement. M. A. H-, aged nineteen, servant, admitted Nov. 13th, 1862. IIl several months with cough; loss of appetite; losing much flesh; occasional streaky hæmoptysis; sputa scanty, mucous; catamenia regular; pulse 90 . Mother died of phthisis.

The physical signs denoted the first stage of tuberculosis in the left ling, the percussion being quite dull under the clavicle, and the respiration there being weak and harsh, with abundant sub-crepitant rhonchi.

Treatment. Half an ounce of syrup of hypophosphite of lime twice, and subsequently three times a day, with liberal diet, and beer. At the end of six weeks no improvement had taken place, and there had been no increase in the weight. Ten minims of the tincture of sesquichloride of iron, with the same quantity of chloric ether, in a little water, was then prescribed, and taken three times a day for six weeks, during which time there was a decided improvement in the general symptoms. The patient was then discharged, calling herself " better," but with. out any improvement in the physical signs. In this case the hypophosphite signally failed, no amelioration, nor indeed any perceptible change, having occurred in any of the symptoms during its administration.

( $T$ o be concluded.)

\section{d.}

OF THE PRACTICE OF

\section{MEDICINE AND SURGERY IN THE}

\author{
HOSPITALS OF LONDON.
}

Nulla est alia pro certo noscendi via, nisi quam plurimas et morborum et dissectionum historias, tam aliorum proprias, collectas habere te inter se comparare.-Moraıgn. De Sed. et Caus. Morb., lib. 14. Procenium.

\section{ROYAL FREE HOSPITAL.}

SYMPTOMS OF ACUTE INTESTINAL OBSTRUCTION FOLLOWED BY DOUBLE PNEUMONIA; PERFORATING ULCER OF THE ANTERIOR WALL OF THE STOMACH; CLINICAL REMARKS.

\section{(Under the care of Dr. Cockx.E.)}

A German housemaid, aged twenty-nin , single, well-formed and moderately well-nourished, of light complexion but not anæmic, was brought into the hospital on the afternoon of the $16 \mathrm{th}$ of March. Having been in her last situation but a fortnight, little was known by those who brought her respecting the general state of her health. It was remembered, however, that she had complained at times of pain in the chest. On the Friday previous she had taken some opening medicine in consequence of the bowels not having acted-an occurrence very uncommon with her. The same night she was seized suddenly with violent pain in the stomach, and vomiting. The whole abdomen soon became swollen, and very tender to the touch. The practitioner who saw her at this juncture, so far as could be ascertained, prescribed calomel and opiam, followed by castoroil and injections. No action of the bowels, however, could be obtained.

At the time of her admission into the hospital, the face was most anxious, expressing great prostration; the abdomen excessively painful, tender, and much meteorized, the pain being described as most acute towards the left hypochondriac region; vomiting was frequent and soon became markedly stercoraceous (feculent fluid); no blood could at any time be traced in the ejected matters; the tongue was dry, and the thirst extreme; there was frequent tenesmus, without the power to effect a passage through the bowels, now without action for four or five days; the bladder was irritable; the pulse small and quick, ranging 130 per minute; respiration somewhat hurried, simply superior thoracic; skin hot and dry; cerebral functions very slightly exalted, probably the effect of opium; pupils moderately contracted, but responsive to the stimulus of light.

The ordinary seats of hernia were carefully explored, as also the vagina and rectum; but such examination failed to reveal the cause of the symptoms. The extreme tenderness and meteorism prevented any minute examination of the abdomen proper. To meet the emergency of the case, so far as practicable, small bits of ice were given frequently, half a grain of solid opium every second hour, and the entire abdomen covered with a linseed-mesil poultice.

On the following day there was but little change in the condition of the patient. To gain an approximative notion as to the height at which obstruction might exist, tepid water was slowly injected into the bowel. About one quart was borne a few minutes, without distress. A portion was then ejecter, mixed with highly offensive fluid of the consistence of gruel. Soon af : erwards a natural evacuation passed in a semi solid state, and at short intervals seven or eight others, the last three being fluid and of a similar character to that brought up by vomiting. Within a few hours from these discharges the most marked amelioration occurred in the more important of the general symptoms: the sickness entirely ceased, and the pain and meteorism very considerably abated; but the left hypochondrium was still the most painful part.

Careful examination of the abdomen now detected circumscribed but extremely well marked swelling and resistance in the right ileo cæcal region. The entire abdomen was still kept covered with linseed-meal poultice; opium continued, but at longer intervals; and small quantities of mild nourishment allowed.

This lull of the abdominal symptoms continued during the three succeeding days; nor, indeed, was it subsequently interrupted. The face, notwithstanding, retained its anxious and distressed expression; the pulse kept weak and rapid; and the tongue, mouth, and lining membrane of the cheeks became gradually coated with a species of aphthous eruption, which rendered it difficult for the patient to articulate. A slight but troublesome cough now supervened, with mucous rale audible at some distance, but the patient had no power to expectorate. Small quantities of wine and ammonia were given. On the fourth morning from the cessation of the more acute abdominal symptoms, the breathing becane suddeuly excessively difficult, the cheeks being deeply flushed with the cyanotic tint of the surrounding skin and lips. The midilay physical examination detected entire soliditication of the base of the left lung, and progressive solidification of the base of the right lung. Death occurred at seven P.M.

The autopsy was made by Mr. Hill, who had most carefully watched the progress of the case. The following are bis notes:- The head was not examined. Chest: S.ight effusion into the pericardial sac; heart very flabby and readily lacerable; lower two thirds of the lower lobe of the lef $\mathrm{c}$ lung perfectly solid, heavily sinking in water; the base of this lung adherent to the diaphragm by a thick layer of recent lymph; the lung was rearily detached without injury to its substince; the base of the right lung extremely congr sted, semi solid portions partially sinking in water; much pleuritic adhesion of the middle lobe. Both the lungs were extremely o lematous in the upper portions, pitting on pressure, and large quantities 